\title{
ANNUAL RAINFALL AND FORECAST OF UTTER PRADESH
}

\author{
KAAMUN $^{1} \&$ NITISH SHARMA ${ }^{2}$ \\ ${ }^{1}$ Research Scholar, Chandigarh University, Mohali, Punjab, India \\ ${ }^{2}$ Assistant Professor, Chandigarh University, Mohali, Punjab, India
}

ABSTRACT
Data of about 50 years i.e. between 1986 and 2017 is analysed in this study for trend determination, forecast as well as different
parametric ad non-parametric tests. These were performed for a data collected by over 100 rain gauge stations of Utter
Pradesh. The results show a minute drop in trend for all months and seasons except August, July and September which leads
to a drop in monsoon trend. This drop can also be seen in seasonal forecast which is done till 2065. The trend as well as
forecast was done using MS-Excel.
KEYWORDS: Forecast, Trend, Rainfall Variation, Rainfall

Received: Jun 01, 2020; Accepted: Jun 20, 2020; Published: Jul 01, 2020; Paper Id.: IJMPERDJUN2020164

\section{INTRODUCTION}

Rainfall is an important meteorological parameter, which has direct application in fields like agriculture and other related sectors of India. These sectors got affected by changes in the availability of water as well as adequate climate. The amount of rainfall in an area helps to meet various demands, including agricultural, industrial, and domestic and hydraulic power generation.

Rainfall is measured in - length per unit time. Rainfall analysis helps in designing and modelling water management studies, rainwater harvesting, estimation of the flood, pond design, groundwater recharge techniques, irrigation plans, evapo transpiration estimation etc. The analysis includes trend analysis, frequency analysis, rainfall intensity, extreme events analysis, future trend prediction etc. Trend analysis is a method that helps in determining the spatial variations and temporal changes for different parameters of climate.

Many researchers have done work regarding trend for different locations, rainfall decencies are found to occur in most parts, except peninsular Indian region. However, the magnitudes of the regional differences in the results are very high. The decency is relatively strong in the north-east, west-central and central north-east India, the regions of usual maximum monsoon rainfall, making the north India most vulnerable to summer droughts. (Pal \& Al-Tabbaa, 2010) Increasing seasonal precipitation trends, decreasing number of rainy days, increasing magnitudes, and rising occurrences of extreme events may have implication on urban water management sector with a lesser number of days to recharge and heavy rainfall days to struggle with the nuisance of urban flooding was found by Bisht, et al. (Bisht et al., 2018a).It is inferred that water resources and agriculture both are at the great risk under the changing climate in the arid region of Western India by Machiwal, et al. (Machiwal et al., 2019). Sinha, et al concluded that the all-India rainfall trend is significantly decreasing in pre-monsoon season and its individual months as well.(Sinha et al., 2019) Investigation by Bisht, et al. reveals that the decreasing trend in annual and monsoonal rainfall has become much profound in the post-urbanization period as compared to the preurbanization era.(Bisht et al., 2018b) 


\section{METHODOLOGY}

Standard Deviation is measured to quantify the amount of variation or dispersion of the set of data values.

Coefficient of Variation measures how a set of numbers are spread out from their average value. It is a non-negative value.

Sen's Slope is the slope of the regression line(Roy \& Balling, 2004).

Kurtosis determines the sharpness of the peak of a frequency distribution curve.

Chi-Square is a test that measures how expectations compare to actual observed data.

Confidence Interval gives upper and lower bounds on the range of parameter value one might expect to get if we repeat our measurement.

Kolmogorov-Simonov Test is a non-parametric hypothesis test of the equality of continuous or discontinuous onedimensional probability distributions that can be used to compare a sample with a reference probability distribution or to compare two samples.(Zhou et al., n.d.)

Mann-Kendall Testis a nonparametric test for defining a trend in a time series without indicating the type of trend, i.e. line aror non linear.(Ramkar \& Yadav, 2019)

The goodness of Fit it tells the extent to which observed data matches the value of expected value by theory

Anderson-Darling Testis a statistical test of whether a given sample of data is drawn from a given probability distribution.

Normality Testis used to determine if a data set is well-modelled or not.

P-P Plot (probability-probability test) it is used to evaluate the skewness of data set.

Q-Q Plot (quantile-quantile test) a graphical method of comparing two probability distributions by plotting their quantities against each other.

\section{RESULTS}

Figure 1 and Figure 2 represent the total annual rain fall of Utter Pradesh for the past 5 decades. However, Figure 2 also gives a brief representation of Sen's slope for the same.

Results can be divided into 4 parts: seasonal variation, monthly variation, seasonal forecast and statistical tests.

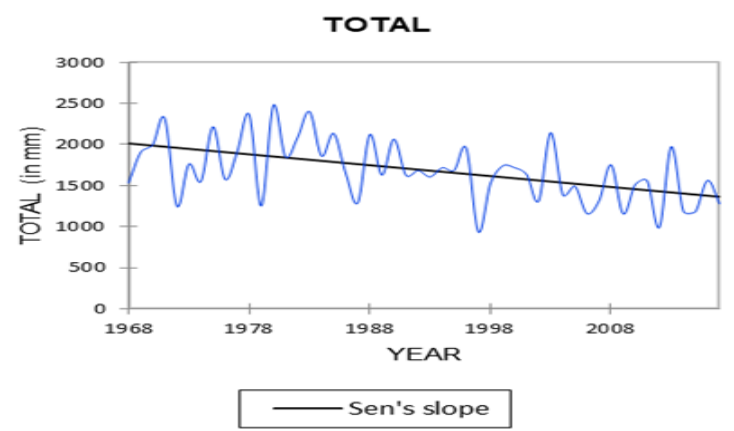

Figure 1: Sen's Slope. 


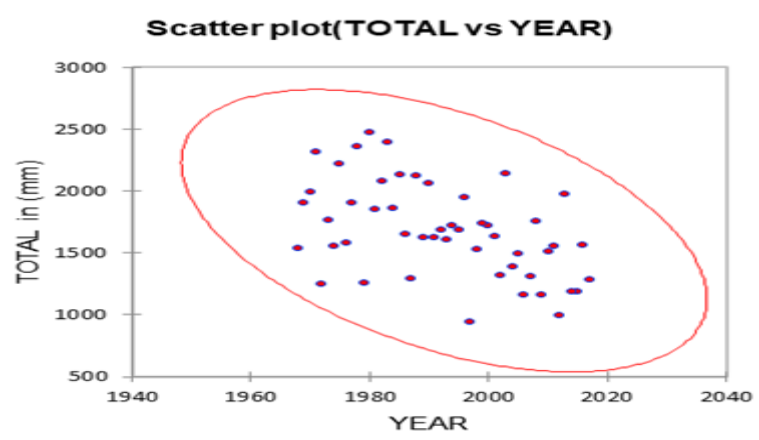

Figure 2: Scatter Plot of Total Annual Rainfall.

\subsection{Seasonal Variation}

Figure 3 to Figure 7 represents the seasonal variation of total rainfall with the trend, moving average and also gives the linear equation for trend as well as coefficient of determination. From the above figures, it can be said that there is a minute decrease in trend for all seasons except monsoon due to which there is a decrease in trend for total annual rainfall.

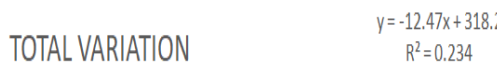

1000

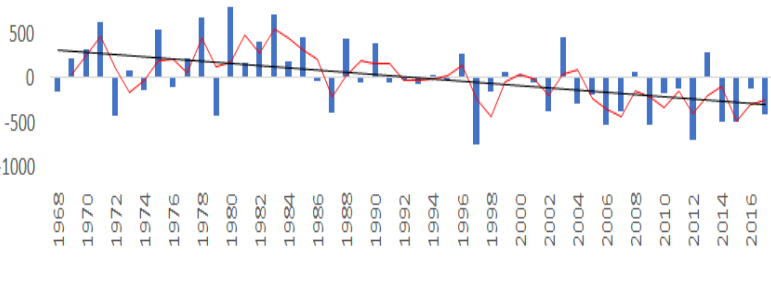

VARIATION - 2 per. Mov. Avg. (VARIATION) - Linear(VARIATION)

Figure 3: Total Rainfall Variation.
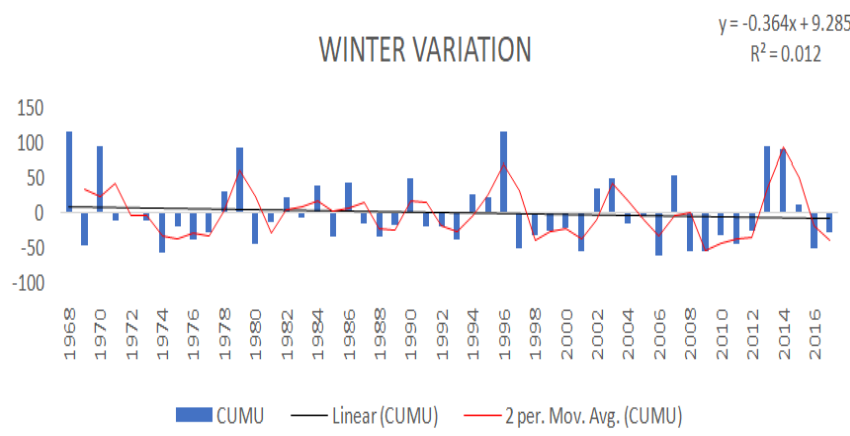

Figure 4: Winter Variation.

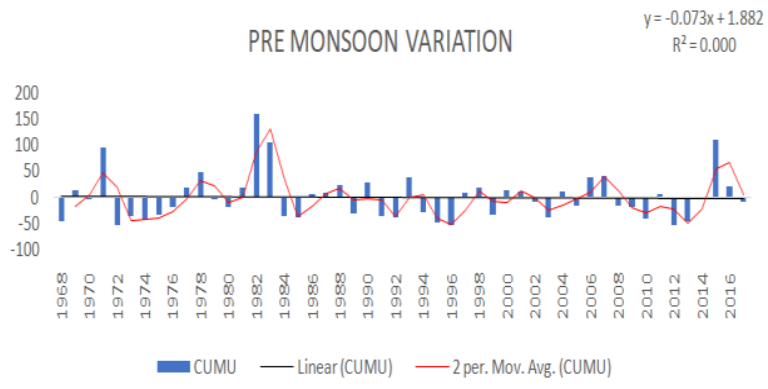

Figure 5: Pre-Monsoon Variation. 


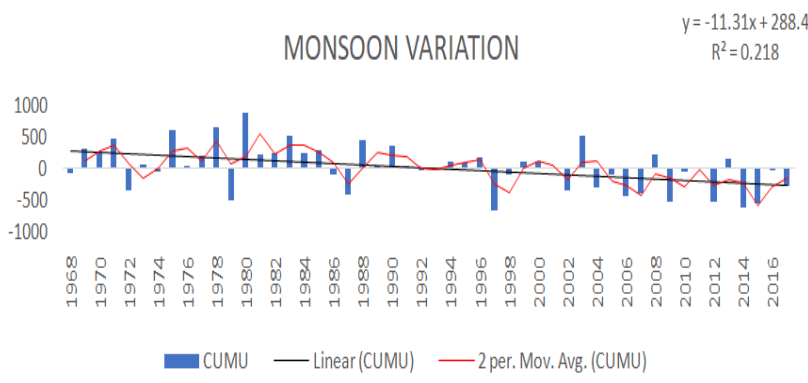

Figure 6: Monsoon Variation.
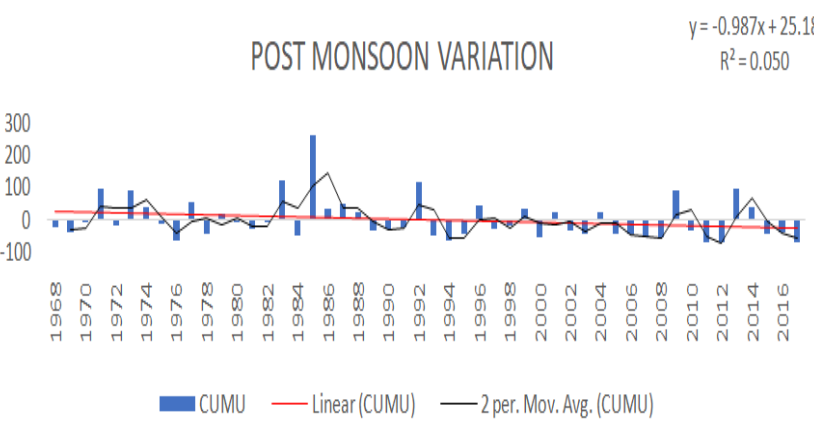

Figure 7: Post-Monsoon Variation.

\subsection{Monthly Variation}

Figure 8 to Figure 19 shows the variation of total rainfall with respect to an average rainfall of the past 5 decades. They also give trend line, moving average along with linear equation as well as coefficient of determination. It can be noted that the maximum decrease in trend is shown in the month of August followed by July and September all other months shows slight drop in trend.

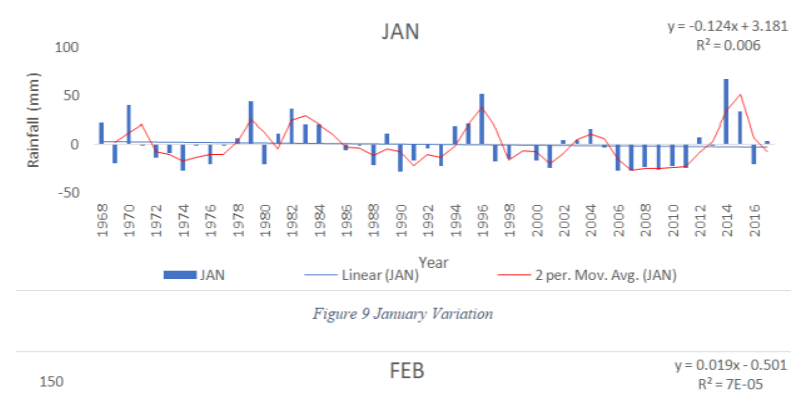

Figure 8: January Variation.

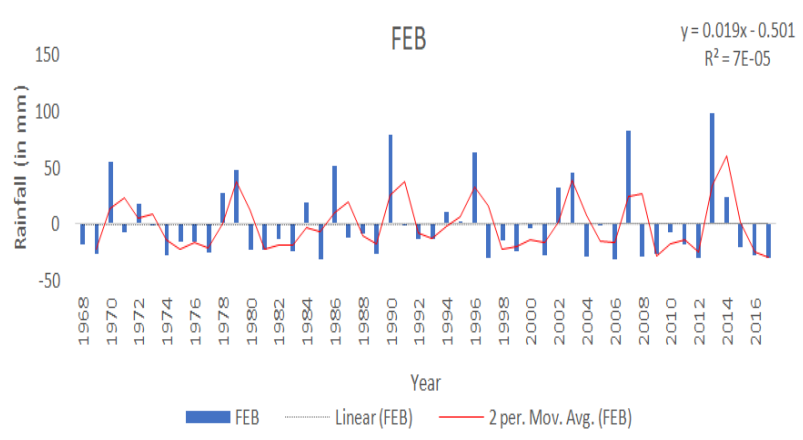

Figure 9: February Variation. 


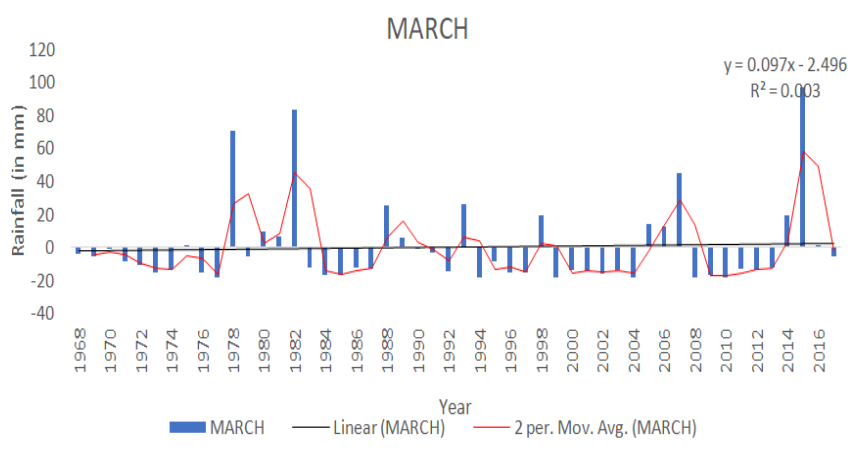

Figure 10: March Variation.

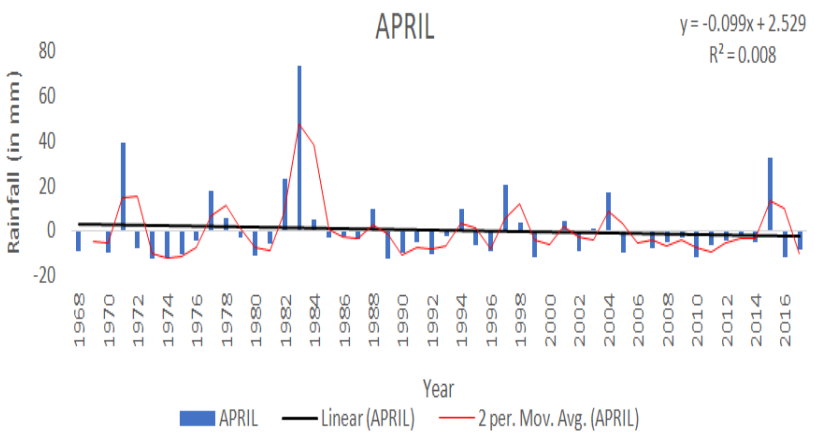

Figure 11: April Variation.

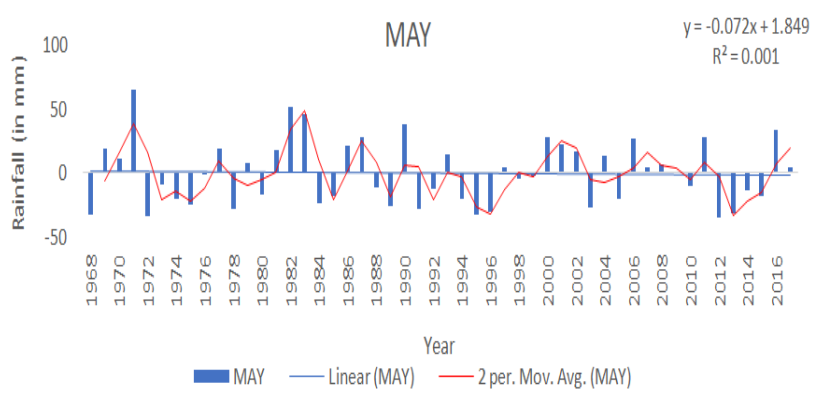

Figure 12: May Variation.

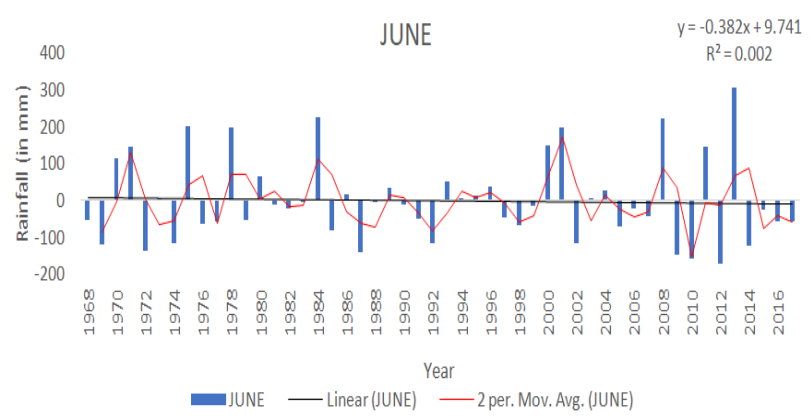

Figure 13: June Variation. 


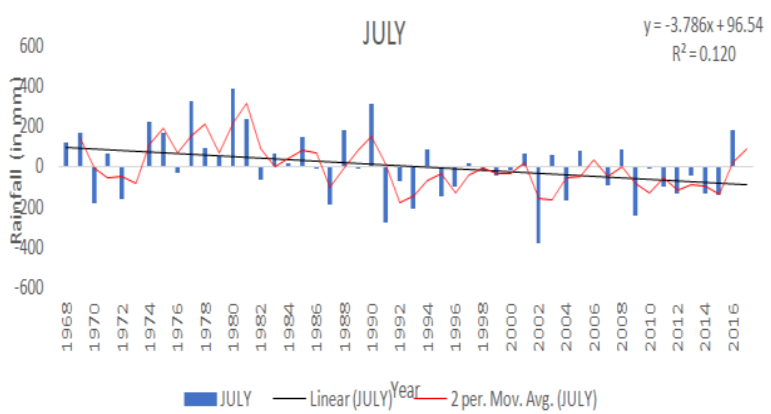

Figure 14: July Variation.

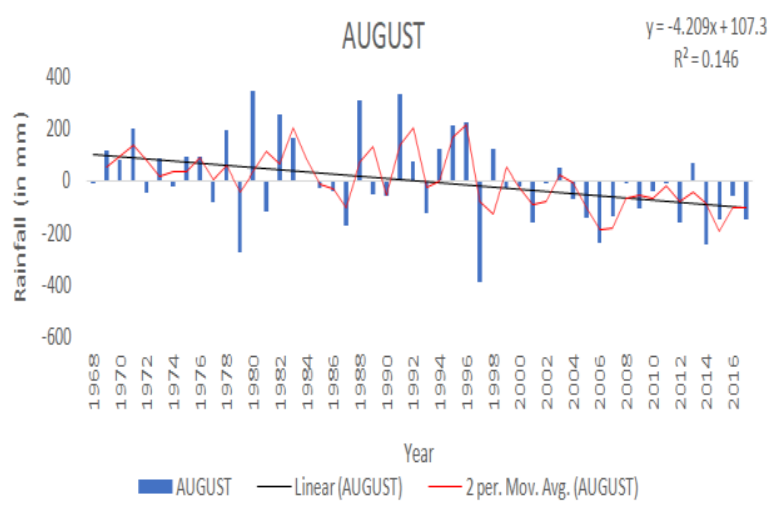

Figure 15: August Variation.

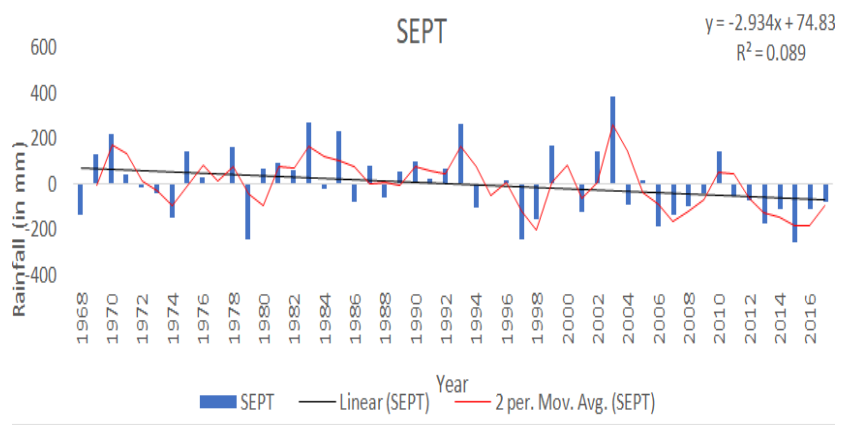

Figure 16: September Variation.

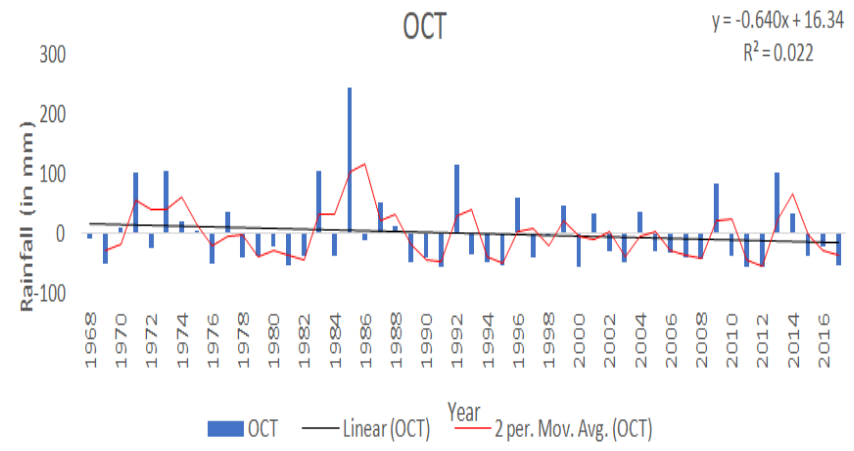

Figure 17: October Variation. 


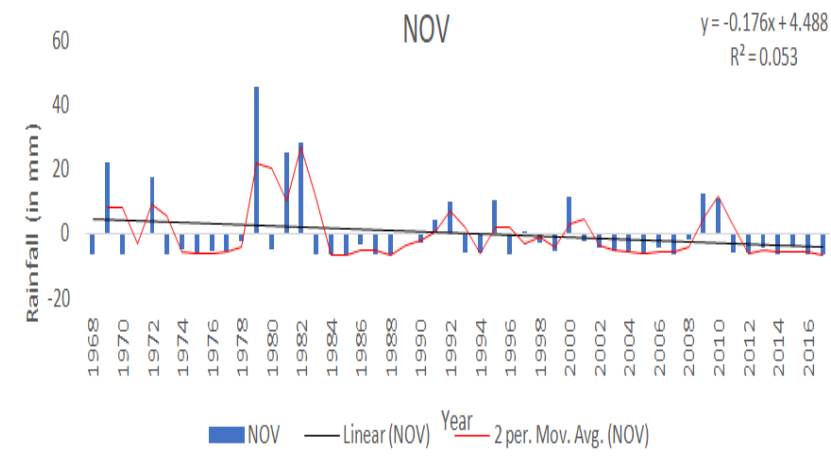

Figure 18: November Variation.

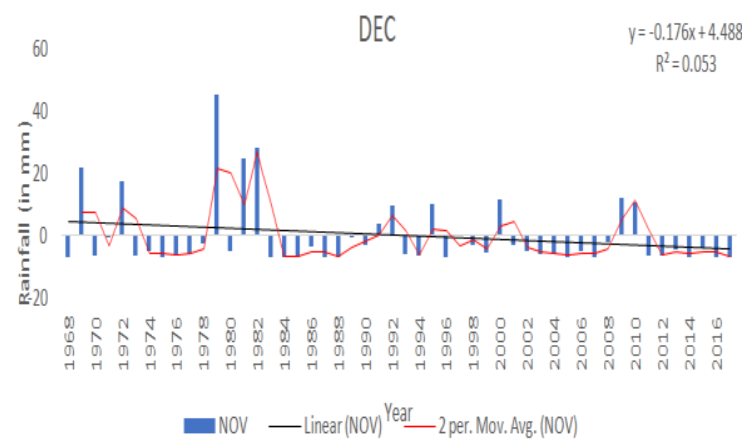

Figure 19: December Variation.

\subsection{Seasonal Forecast}

Figure 25 Shows it was found that the slope of the trend using Mann-Kendell's tend test was -401.00 also in accordance with goodness of Fit $\mathrm{R}^{2}$ is 0.155 . If the normality tests us taken into account, mu1 and mu2 are 1843 and 1455 respectively.

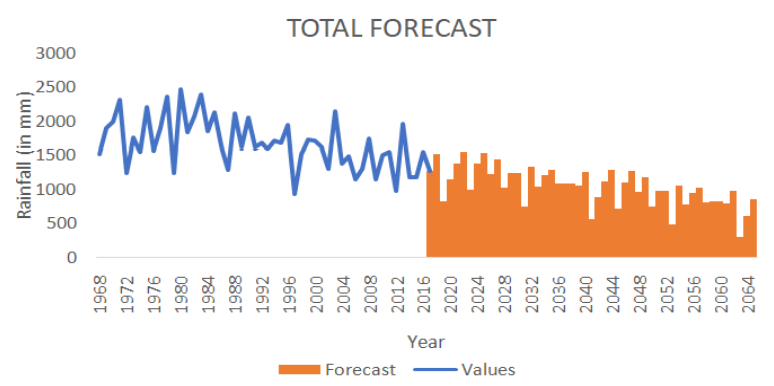

Figure 20: Total Rainfall Forecast.

Table 1: Total Rainfall Statistic

\begin{tabular}{|c|c|}
\hline Statistic & Value \\
\hline Alpha & 0.251 \\
\hline Beta & 0.001 \\
\hline Gamma & 0.25 \\
\hline MASE & 0.688 \\
\hline SMAPE & 0.217 \\
\hline MAE & 321.437 \\
\hline RMSE & 378.685 \\
\hline
\end{tabular}




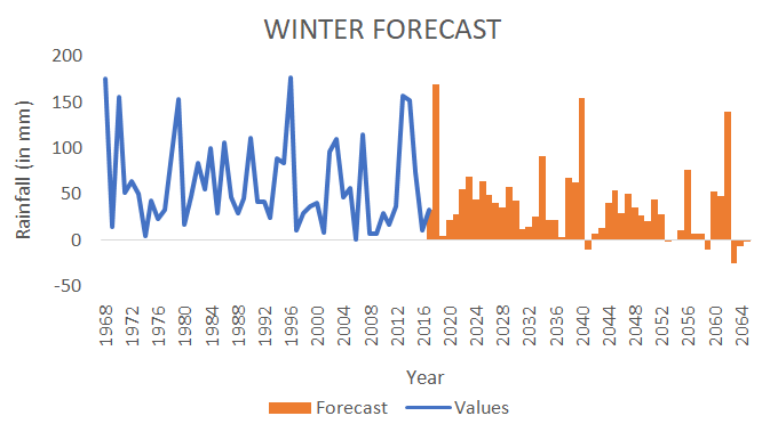

Figure 21: Winter Forecast.

Table 2: Winter Statistic

\begin{tabular}{|c|c|}
\hline Statistic & Value \\
\hline Alpha & 0.251 \\
\hline Beta & 0.001 \\
\hline Gamma & 0.001 \\
\hline MASE & 0.771 \\
\hline SMAPE & 0.853 \\
\hline MAE & 44.032 \\
\hline RMSE & 57.373 \\
\hline
\end{tabular}

PREMONSOON FORECAST

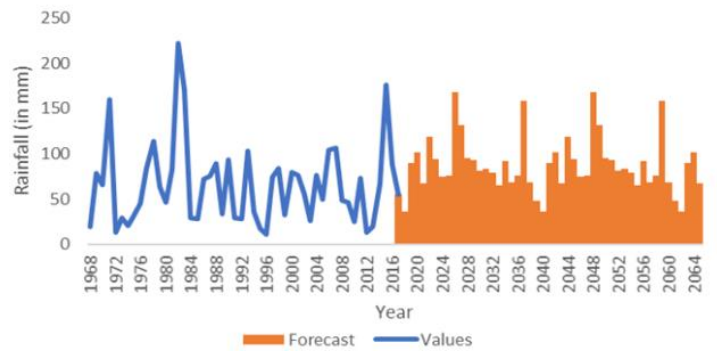

Figure 22: Pre-Monsoon Forecast.

Table 3: Pre-Monsoon Statistic

\begin{tabular}{|c|c|}
\hline Statistic & Value \\
\hline Alpha & 0.251 \\
\hline Beta & 0.001 \\
\hline Gamma & 0.25 \\
\hline MASE & 0.837 \\
\hline SMAPE & 0.659 \\
\hline MAE & 38.749 \\
\hline RMSE & 47.089 \\
\hline
\end{tabular}

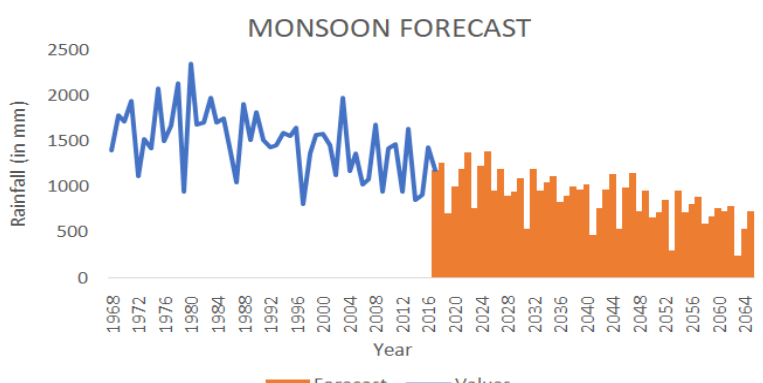

Figure 23: Monsoon Forecast. 
Table 4: Monsoon Statistic

\begin{tabular}{|c|c|}
\hline Statistic & Value \\
\hline Alpha & 0.251 \\
\hline Beta & 0.001 \\
\hline Gamma & 0.25 \\
\hline MASE & 0.749 \\
\hline SMAPE & 0.227 \\
\hline MAE & 296.244 \\
\hline RMSE & 353.122 \\
\hline
\end{tabular}

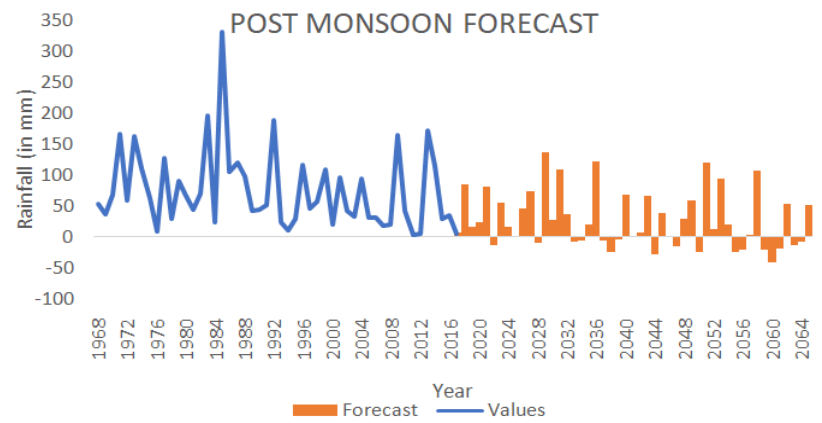

Figure 24: Post Forecast.

Table 5: Post-Monsoon Statistic

\begin{tabular}{|c|c|}
\hline Statistic & Value \\
\hline Alpha & 0.002 \\
\hline Beta & 0.001 \\
\hline Gamma & 0.125 \\
\hline MASE & 0.481 \\
\hline SMAPE & 0.881 \\
\hline MAE & 37.788 \\
\hline RMSE & 56.583 \\
\hline
\end{tabular}

3.4. Statistical Tests

Table 6: Statistical Results

\begin{tabular}{|l|c|l|c|}
\hline \multicolumn{2}{|c|}{ Basic Statistics } & \multicolumn{2}{c|}{ Mann-Kendall Trend Test } \\
\hline Total & 83986.8 & Kendall's tau & -0.327 \\
\hline Average & 179.7 & S & -401.000 \\
\hline Max & 2473.2 & Var (S) & 14291.667 \\
\hline Kurtosis & -0.56 & p-value & 0.001 \\
\hline Skewness & 0.17 & Alpha & 0.05 \\
\hline Variance & 138178.64 & \multicolumn{2}{c|}{ Chi-Square Test } \\
\hline Trend & 1985.47 & Chi-square (Observed Value) & 3.650 \\
\hline Standard Deviation & 371.72 & Chi-square (Critical Value) & 14.067 \\
\hline Confidence & 35.81771 & DF & 7 \\
\hline \multicolumn{2}{|c|}{ Kolmogorov-Smirnov Test } & p-value & 0.819 \\
\hline D & 0.075 & Alpha & 0.05 \\
\hline p-value (Two tailed) & 0.923 & \multicolumn{2}{c|}{ Goodness of Fit } \\
\hline Alpha & 0.05 & R & 0.155 \\
\hline \multicolumn{2}{|c|}{ Anderson Darling Test } & SSE & 5826442.487 \\
\hline A $^{2}$ & 0.276 & MSE & 118906.990 \\
\hline p-value & 0.643 & RMSE & 344.829 \\
\hline
\end{tabular}



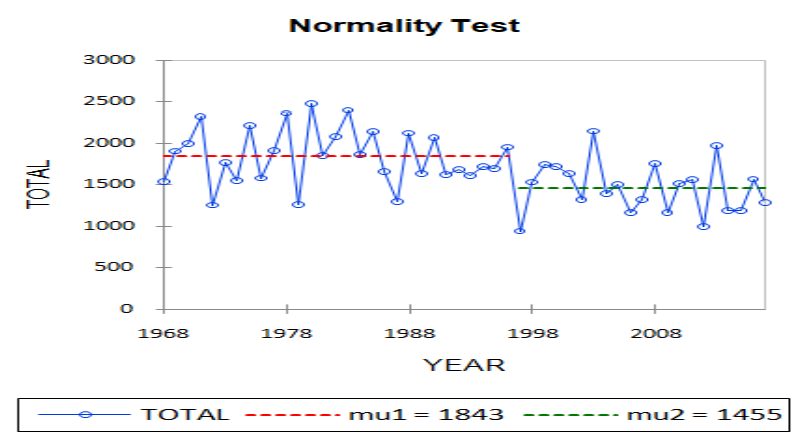

Figure 25: Normality Test.

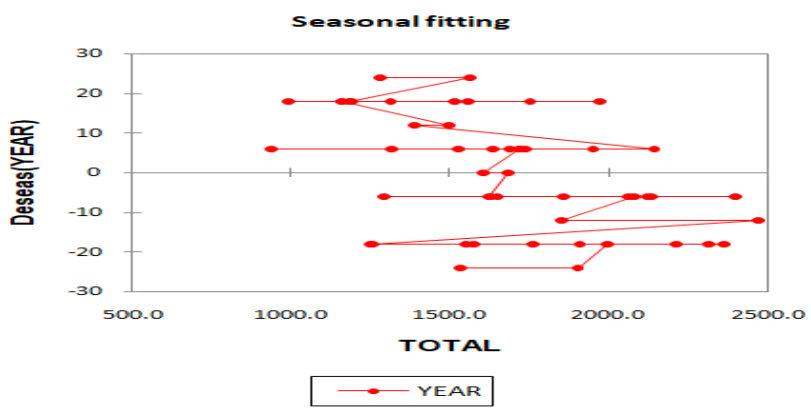

Figure 26: Seasonal Fitting.

\section{DISCUSSIONS}

- There is a decreasing trend in total annual rainfall.

- There is a significantly large drop in rainfall in monsoon season than other seasons.

- Annual rainfall forecast also shows a decreasing trend, this drop is larger in monsoon as compared to other seasons.

- If looked in monthly total precipitation the largest variation or decrease in trend is in the month of August followed by July.

\section{REFERENCES}

1. a. A.-T. A. Pal, "Regional changes in extreme monsoon rainfall deficit and excess in India," Dyn. Atmos. Oceans, 2009.

2. a. A.-T. A. Pal, "Trends in seasonal precipitation extremes - an indicator of climate change in Kerala," India. J. Hydrol, pp. 6269,2009

3. D. R. a. R. M. Pattanaik, "Variability of extreme rainfall events over India during southwest monsoon season.," Meteorol. Appl., p. 88-104, 2010.

4. N. S. A. K. a. R. M. H. S. Subash, "An investigation into observational characteristics of rainfall and temperature in Central Northeast India - a historical perspective 1889-2008.," Theor. Appl. Climatol.,, 2010.

5. H. S. D. Rahman, "Preliminary comparison of daily rainfall from satellites and Indian gauge data.," CAOS Technical Report, 2007.

6. H. Mann, "Nonparametric tests against trend.," Econometrica, p. 245-259, 1945.

7. P. Sen, "Estimates of the regression coefficient based on Kendall's Tau.," J. Am. Stat. Assoc., pp. 1379-1389, 1968.

8. Thupeng, Wilson Moseki. "STATISTICAL MODELLING OF ANNUAL MAXIMUM RAINFALL FOR BOTSWANA USING EXTREME VALUE THEORY." International Journal of Applied Mathematics \& Statistical Sciences (IJAMSS) 8.2 (2019):110. 
9. KULKARNI, NAHUSH, et al. "CASE STUDY: IMPACT OF MEAN MONTHLY DIURNAL TEMPERATURE VARIATION AND RAINFALL EVENTS ON THE OCCURRENCE OF MALARIA CASES AND PREPARATION OF DISEASE TRANSMISSION WINDOW IN KOLHAPUR DISTRICT." International Journal of Environment, Ecology, Family and Urban Studies (IJEEFUS) 9.2 (2019):6982.

10. Sahewalla, I. P., et al. "Impact of Rainfall and Temperature on Tea Production in Undivided Sivasagar District." International Journal of Agricultural Science and Research (IJASR) 8.1 (2018): 5156.

11. DWIVEDI, DK, GR SHARMA, and DV PATEL. "IDENTIFICATION OF RAINFALL PROBABILITY DISTRIBUTION FOR JUNAGADH." International Journal of Agricultural Science and Research (IJASR) 7.2 (2017):521528.

12. VORA, VD, et al. "RAINFALL ANALYSIS FOR CROP PLANNING IN NORTH SAURASHTRA AGRO-CLIMATIC ZONE." International Journal of Agricultural Science and Research (IJASR) 6.5 (2016):307320.

13. Goyal, Megha, and Urmil Verma "WEATHER BASED WHEAT YIELD FORECASTING IN EASTERN ZONE OF HARYANA." International Journal of Applied and Natural Sciences (IJANS) 7.4 (2018):1922.

14. Goyal, Megha. "PRE-HARVEST WHEAT YIELD FORECAST THROUGH AGRO-METEOROLOGICAL INDICES FOR NORTHERN REGION OF HARYANA." International Journal of Applied Mathematics Statistical Sciences (IJAMSS) 7.3 (2018):2940. 

